\title{
Analysis of photovoltaic system with battery storage in winter period
}

\author{
Jan Lokar $^{1}$, and Peter Virtič ${ }^{1, *}$ \\ ${ }^{1}$ Faculty of Energy Technology, University of Maribor, Hočevarjev trg 1, 8270 Krško, Slovenia
}

\begin{abstract}
Energy sources as a solar, wind and water energy are used in production of electrical energy. Their biggest advantage is that they are renewable and they are sustainable. On the other hand, production from renewable energy sources is limited by environmental conditions. Production of photovoltaic systems are dependent on solar radiation, temperature, incidence angle, shadowing and other variable quantities. That is why designing of photovoltaic system is complex. In this paper a photovoltaic system production analysis and consumption analysis in residential house are presented. With real measured data the consumption and production are compared and energy balance equations, battery charge and discharge model are defined and behaviour of battery storage system through the one day are analysed. In addition, the reactive energy production and consumption are also analysed.
\end{abstract}

\section{Introduction}

A clear tendency moving towards renewable energy is observed since the end of the twentieth century, in response to an early depletion of oil supply, to climate and environmental impacts of carbon energies [1]. Solar energy is considered as one of the most important renewable source of energy because of the huge amount of free energy source, without emissions during energy production, almost maintenance free and becoming more and more promising [2]. Energy production with photovoltaic systems is not available all the time. Production depends on solar radiation, temperature, incidence angel, shadowing and other quantities, which are under the influence of environment. In recent years, introducing the battery storage systems are becoming more popular, but energy storage elements are nowadays expensive, breakable and allow low performances [3], so the most efficient system to harvest energy from alternative sources is still the injection into the grid $[4,5]$.

Due to their dependence on weather conditions, the renewable energy sources, including photovoltaic systems, have a stochastic production that makes it difficult to integrate into the electric grid. Uncoordinated massive integration leads to destabilization of the grid [6], so this is one of the reasons, why designing a photovoltaic systems can be complex task. By introducing energy storage systems destabilization problem of the grid can be solved, but as we described previously, energy storage systems have many other disadvantages.

\footnotetext{
*Corresponding author: peter.virtic@um.si
} 
As designing of photovoltaic systems is based on the amount of solar radiation, the effects of natural conditions on photovoltaic system production have to be analysed, in our case the effect of temperature and solar radiation. For our photovoltaic system a scheme of power flow has to be created and basic energy balance equations set. After that the consumption in pilot building, which is usual residential house, is analysed and deficit energy is calculated. In relation with energy production, the operation of battery storage system is also analysed.

\section{Method for analysis of photovoltaic system with battery storage}

This part of paper represents pilot photovoltaic system with battery storage unit in pilot building (residential house), where battery control algorithm was in the self-consumption mode. State of charge was measured through the measurement of battery voltage level with industrially in-built sensor.

\subsection{Energy balance}

A scheme of our system is represented on Fig. 1.

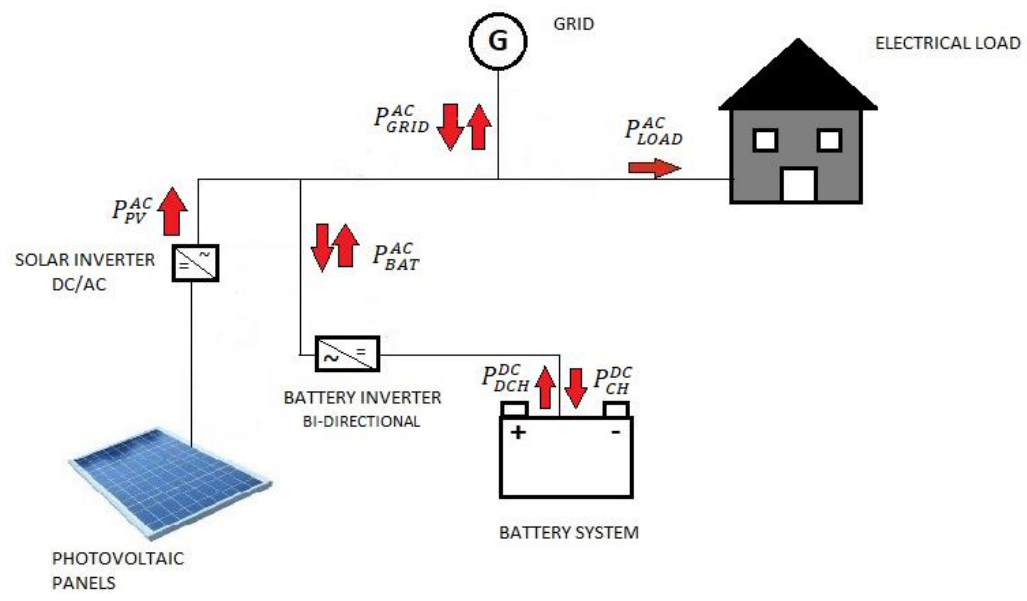

Fig. 1. Scheme of photovoltaic system with battery storage.

According to Fig. 1 and [7, 8] equations of energy balance can be derived. The power dispatched from the photovoltaic system is represented by two components, one for consumption of the building and one for battery charging at time $t$ [7]. Equation (1) presents balance equation of grid connected photovoltaic system with storage and consumption at time $t[9]$.

$$
P_{P V}^{A C}(t) \pm P_{G R I D}^{A C}(t)=P_{L O A D}^{A C}(t) \pm P_{B A T}^{A C}(t)
$$

where $P_{P V}^{A C}(t)$ is power produced PV energy measured on AC side of inverter, $P_{G R I D}^{A C}(t)$ is power injected to or taken from the grid, $P_{L O A D}^{A C}(t)$ is consumption power of the building and $P_{B A T}^{A C}(t)$ is the power measured on AC side for charging or discharging the battery. It can be seen that there are four possible combination of power flow. 
It is possible to take into account also the efficiency of battery presented in (2)-(3) and PV inverter presented in (4) [10].

$$
\begin{gathered}
\text { charging: } P_{C H}^{D C}(t)=\eta_{B A T A C / D C} \cdot P_{B A T}^{A C}(t) \\
\text { discharging: } P_{B A T}^{A C}(t)=\eta_{B A T D C / A C} \cdot P_{D C H}^{D C}(t) \\
P_{P V}^{A C}(t)=\eta_{P V A C / D C} \cdot P_{P V}^{D C}(t)
\end{gathered}
$$

where $\eta_{B A T A C / D C}$ is efficiency of battery inverter at charging, $\eta_{B A T D C / A C}$ is efficiency of battery inverter at discharging, $\eta_{P V A C / D C}$ is efficiency of PV inverter, $P_{D C H}^{D C}$ is DC power at battery discharging and $P_{C H}^{D C}(t)$ is DC power at battery charging.

Because this paper analyses the energy/power balances on $\mathrm{AC}$ side between $\mathrm{PV}$ production, consumption, battery storage and grid in the mode of self-consumption, we could take into account only the power on the AC side of inverters.

\subsection{Battery charge and discharge model}

The biggest restriction of battery is the capacity. An important thing is also the efficiency of energy conversion of electric to chemical energy and vice versa. With time it appears also fade of battery capacity. The equations written below are presenting battery stored energy during the time and the restrictions of the capacity that depends on the fade factor [7].

$$
Q_{B}(t+1)=Q_{B}(t)+\eta_{R} \cdot P_{C H}^{D C}(t)-P_{D C H}^{D C}(t)
$$

where $Q_{B}$ is battery stored energy, $\eta_{R}$ is the efficiency of energy conversion from electric to chemical energy, $P_{C H}^{D C}(t)$ is battery charging power at $t$ and $P_{D C H}^{D C}(t)$ is battery discharging power at $t$. Battery capacity fade depends on coefficient of fade and the power of discharging. With each discharge, battery loses [7].

$$
Q_{f}(t+1)=Q_{f}(t)+Z_{b} \cdot P_{D C H}^{D C}(t)
$$

where $Q_{f}(t)$ is capacity fade at time $t, Z_{b}$ is degradation factor of the considered battery technology. Power of charging and discharging is also limited.

$$
P_{C H}^{D C}(t) \leq N_{B} \cdot \overline{P_{B}}
$$

where $\overline{P_{B}}$ is maximum charge/discharge power per $\mathrm{kWh}$ and $N_{B}$ is installed battery capacity in $\mathrm{kWh}$. The equation (7) is used also for discharging power.

\subsection{Basic data about photovoltaic system with battery storage}

Basic data of photovoltaic system with battery storage are presented in Table 1.

Table 1. Basic data about photovoltaic system and battery storage.

\begin{tabular}{|c|c|c|c|}
\hline \multicolumn{2}{|c|}{ Photovoltaic system } & \multicolumn{2}{c|}{ Battery unit } \\
\hline Installed power & $6.72 \mathrm{kWp}$ & Installed capacity & $6.6 \mathrm{kWh}$ (usable) \\
\hline Module type & SolarREC280PE & Inverter efficiency & $98.8 \%$ \\
\hline Number of modules & $24 \times 280 \mathrm{Wp}$ & Depth of discharge & $<95 \%$ \\
\hline Inverter type & Solar Edge $7 \mathrm{~K}(7 \mathrm{~kW})$ & $\begin{array}{c}\text { DC round trip } \\
\text { efficiency }\end{array}$ & $95 \%$ \\
\hline Inverter efficiency & $97.3 \%$ & Number of cycles & 6000 \\
\hline
\end{tabular}




\subsection{Data acquisition}

Data acquisition is based on monitoring system of different variables. All of them are measured every 15 minutes. Measured variables are: production of electricity from Photovoltaic system, charging/discharging of battery, import/export of electricity from the grid, consumption of electricity, active/reactive energy production/consumption.

\section{Results and discussion}

In this chapter analysis results of different variables through the analyzation period are presented. Chosen analyzation period was from 1.12.2018 to 1.1.2019. Daily production and consumption of active energy are presented in Fig. 2.

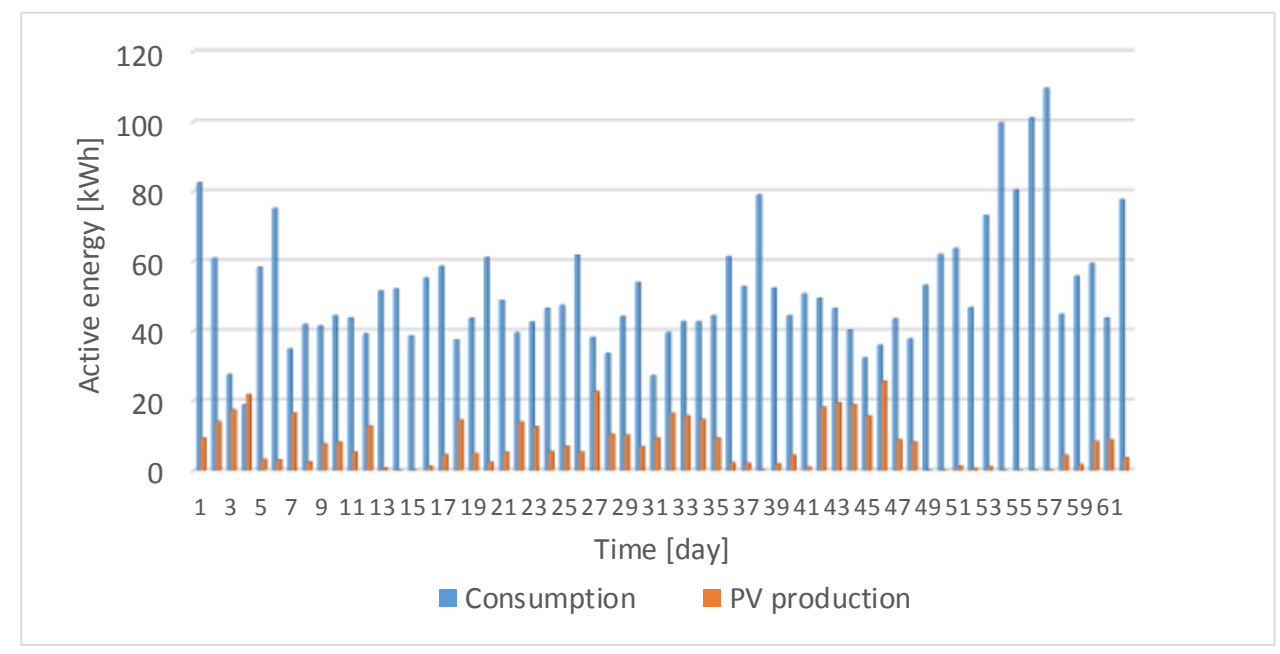

Fig. 2. Daily production and consumption of active energy.

According to Fig. 2, there was just one day in whole analyzation period, when energy production was higher than consumption. On the other days, consumption was higher than production. It was also noticed that the consumption during the weekends is higher than during the week. Fig. 3 represents daily production and consumption of reactive energy.

A production of reactive energy was higher than consumption on the load side through the whole analyzation period. There was no need to take a reactive energy from the grid. Fig. 4 represents energy production, energy consumption and State of charge of battery system through the one day of our analyzation period.

When production is higher than pilot consumption, state of charge is rising and vice versa. As a period of energy production was shorter than in summer time, state of charge of pilot battery system did not reach maximum state of charge. 


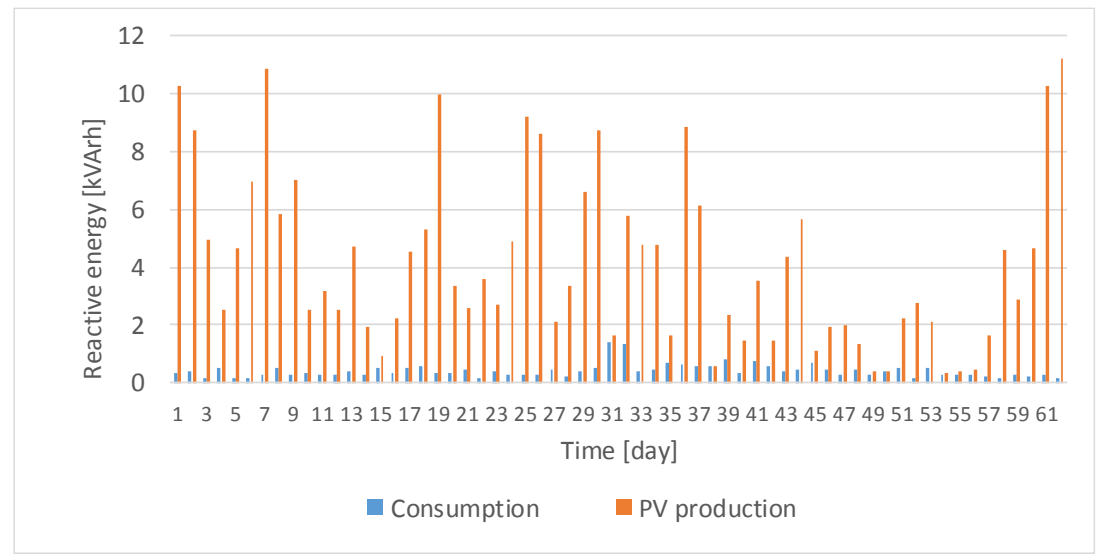

Fig. 3. Daily production and consumption of reactive energy.

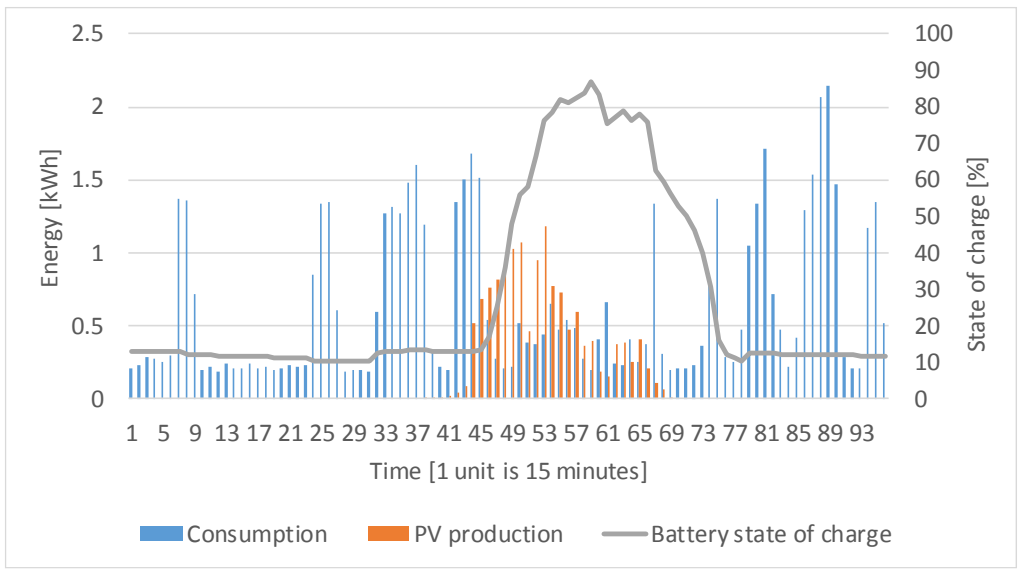

Fig. 4. Influence of the relation between consumption and production on state of charge of battery system.

Fig. 5 presents the power and state of charge dependency for sample day $31^{\text {st }}$ of December. It can be seen that battery is not completely charged but only up to $79.5 \%$. Stored energy is in the evening discharged in approximately $1.5 \mathrm{~h}$. As the battery control algorithm was for self-consumption, battery was discharging with maximum allowed power of $3.5 \mathrm{~kW}$ but it was charging with a little bit lower power than maximum as surplus power from PV was not high enough. 


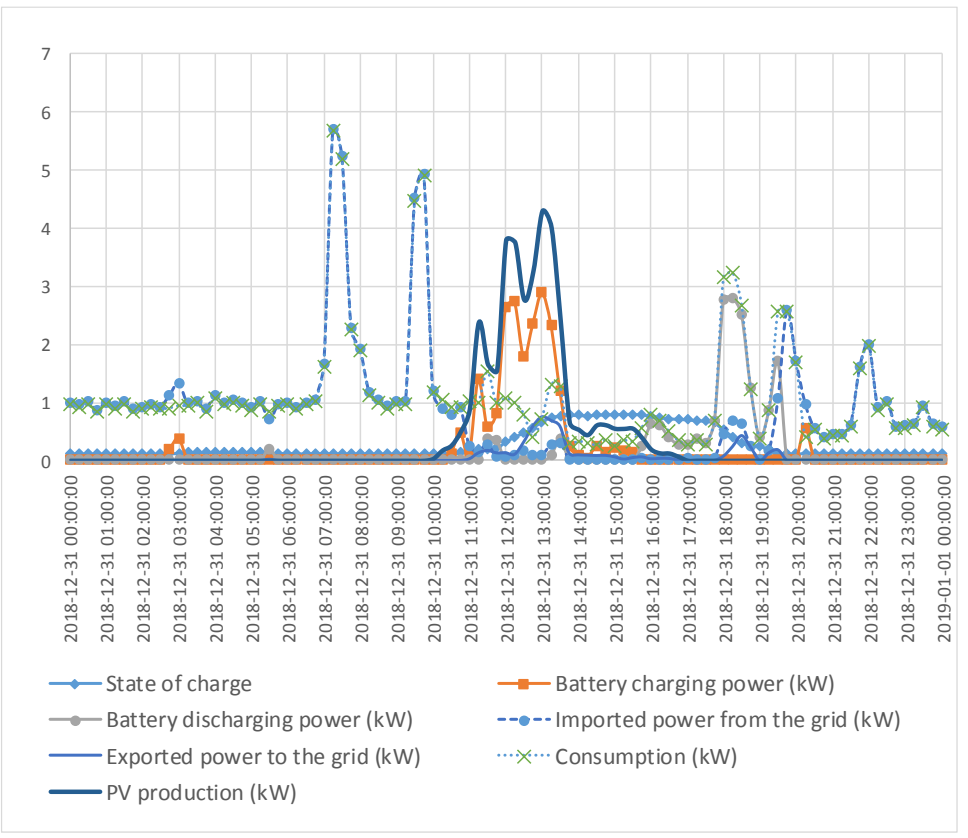

Fig. 5. State of charge and power (grid, battery, consumption, PV production) for $31^{\text {th }}$ of December 2018.

\section{Conclusion}

According to the results of analysis there is no possibility to provide complete self-sufficiency through the winter period, because energy production is most of the time lower than consumption. It was analysed the most problematic period of the year for energy production with photovoltaic system and most of energy had to be provided from the grid. To provide a complete self-sufficiency an introducing of hybrid systems such as a hybrid system with fuel cells and photovoltaic system can be a solution. Battery storage systems can save limited amount of energy and they cannot provide energy for longer periods, when production with photovoltaic system is not available.

The research presented in this paper has been partially financed by the Interreg MED Programme, with the project "Promotion of higher penetration of distributed PV through storage)", acronym: StoRES.

\section{References}

1. A. Tazarine, H. El Omari, Designing of a photovoltaic system for self-consumption at the faculty of technical sciences of Settat (International Renewable and Sustainable Energy Conference (IRSEC), Marrakech, 171-176, 2016)

2. K. S. Akash, K. Sudhakar, B. Prashant, Energy Reports 2, 82-88 (2016)

3. J. Selvaraj, N. A. Rahim, IEEE Trans. on Ind. Elecron. 56, 1, 149-158 (2009)

4. L. Dong-Jing, W. Li, IEEE Trans. on En. Conv. 23, 1, 311-320, (2008)

5. P. Lambruschini, M. Raggio, R. Bajpai, A. Sharma, Supervision analysis and control system of photovoltaic power plants $\left(7^{\text {th }}\right.$ International Conference on System of Systems Engineering (SoSE), Genova, 1-4, 2012) 
6. H. Turker, P. Favre-Perrod, Management, optimal sizing and technical-economic analysis of batteries for constant production in photovoltaic systems (IEEE International Conference on Renewable Energy Research and Applications (ICRERA), Birmingham, 1055-1061, 2016)

7. R. Atia, N. Yamada, IEEE Trans. Smart Grid 7, 3, 1204-1213 (2016)

8. C. Prapanukool, S. Chaitusaney, An appropriate battery capacity and operation schedule of battery energy storage system for PV Rooftop with net-metering scheme $\left(14^{\text {th }}\right.$ International Conference on Electrical Engineering/Electronics, Computer, Telecommunications and Information Technology (ECTI-CON), Phuket, 222-225, 2017)

9. N. Pandiarajan, M. Ranganath, Viability analysis on photovoltaic configurations (TENCON IEEE Region 10 Conference 1-5, 2008)

10. V. Vega-Garita, D. De Lucia, N. Narayan, L. Ramirez-Elizondo, P. Bauer, PV-battery integrated module as a solution for off-grid applications in the developing world (IEEE International Energy Conference (ENERGYCON), Limassol, 1-6, 2018) 